\title{
Materiais de descarte das Micro e Pequenas Confecções - Uma proposta de procedimento para o desenvolvimento de produtos sustentáveis na indústria têxtil
}

Scrap materials of Micro and small Clothing - A proposal for a procedure for the development of sustainable products in the textile industry

Fernanda Marinho Pereira da Silva

Mestre em Têxtil e Moda na Escola de Artes, Ciências e Humanidades da Universidade de São Paulo fernandamarinho1978@uol.com.br

\section{Regina Aparecida Sanches}




\title{
Materiais de descarte das Micro e Pequenas Confecções - Uma proposta de procedimento para o desenvolvimento de produtos sustentáveis na indústria têxtil
}

\author{
Scrap materials of Micro and small Clothing - A proposal for a procedure for the \\ development of sustainable products in the textile industry
}

Fernanda Marinho Pereira da Silva e Regina Aparecida Sanches

\section{Resumo}

Esta pesquisa teve como objetivo propor procedimentos, utilizando como referência a metodologia projetual de Löbach para desenvolvimento de produtos sustentáveis têxteis a partir de sobras dos materiais das micro e pequenas confecções. A Metodologia utilizada foi a pesquisa bibliográfica - que constitui o procedimento básico para os estudos monográficos - e a pesquisa exploratória, pois não requer a formulação de hipóteses para serem testadas. Ela se restringe por definir objetivos, buscar mais informações sobre determinado assunto de estudo e identificar qual o melhor método a ser utilizado. No caso deste projeto, a ideia foi adaptar a sintetização de Löbach no processo de design, relacionando-o com o processo de resolução de problemas e o processo criativo, em quatro iniciativas essenciais: definir claramente o problema (preparação); reunir informações sobre o problema, analisá-las e relacioná-las criativamente entre si (geração); criar alternativas de soluções para o problema, julgando-as segundo critérios estabelecidos (avaliação) e desenvolver a alternativa mais adequada, concretizando-a (realização). Após a elaboração do projeto, comprovou-se que a metodologia utilizada se mostrou viável para o desenvolvimento de produtos sustentáveis, voltados para a sociedade e consumo.

Palavras- chave: Design Social, Löbach, processo produtivo, sustentabilidade.

\begin{abstract}
These premises, this research aimed to propose procedures, using as a reference the design methodology of Löbach for development of sustainable textile products from leftovers from materials of micro and small manufacturing. The methodology used was bibliographical research to which constitutes the basic procedure for the monographic studies and exploratory research because it does not require the formulation of hypotheses to be tested. She is restricted by set goals, get more information about a particular subject to study and identify the best method to be used, in the case of this project, the idea was to adapt the Löbach synthesis in the design process, linking it with the problemsolving process and the creative process, on four key initiatives to clearly define the problem (preparation); gather information about the problem, analyze them and relate them creatively with each other (generation); create alternative solutions to the problem, judging the second criteria (evaluation) and develop the most suitable alternative, establishing the (realization). After the elaboration of the project proved that the methodology used proved to be viable for the development of sustainable products, geared to society and consumption.
\end{abstract}

Keywords: Social, Löbach Design, production process, sustainability. 


\section{INTRODUÇÃ̃O}

Segundo Berlin (2012), de todos os itens consumidos por nossa sociedade, a vestimenta tem um significado de suma importância, pois além de nos proteger, configura-se como meio de comunicação.

Vestimenta e moda não possuem o mesmo significado. De acordo com Fletcher (2010), identificam-se como entidades diversas que contribuem para o bem-estar do ser humano. Enquanto a roupa está relacionada com a produção material, a moda está relacionada à identidade contemporânea e individual de cada sujeito e manifesta nossos desejos e nossas emoções (imaterial). Muitas vezes, os conceitos acabam por definir qual o papel de uma peça de roupa na sociedade ou na aparência de uma pessoa ou de um grupo, mas ambos os termos são apresentados a nós de maneiras diferentes (FLETCHER, 2010).

A indústria têxtil e a moda apresentam duas identidades diferentes, entretanto fazem parte de uma mesma unidade e, ao associarmos esse conceito, conforme explicado por Berlin (2012), verifica-se o surgimento de uma área que soma as necessidades materiais e funcionais com as imateriais, adequando matérias-primas, formas, funcionalidade, durabilidade e qualidade às necessidades emocionais expressadas na moda. Pode-se até afirmar que o ato de se vestir, depois do surgimento da moda, ganhou poder comportamental a ponto de traçar a busca de sua identidade.

Segundo a Associação Brasileira da Indústria Têxtil e de Confecção (ABIT), a indústria têxtil nacional tem, aproximadamente, 200 anos, e se posiciona como o quinto maior produtor mundial. Segundo IEMI (2014), o Brasil possui $30.080^{1}$ empresas dedicadas à transformação da matéria-prima em produto a ser utilizado pelo consumidor, sendo que 19.881 são registradas como microempresas, e 7.381 , como empresas de pequeno porte. A indústria têxtil emprega 1.317.377 pessoas e produz um total de 9.458.583 peças por ano (IEMI, 2014).

Segundo Berlim (2012), o crescimento desenfreado trouxe o desenvolvimento industrial e danos à humanidade. O meio ambiente foi sacrificado, colocando em risco a viabilidade futura da humanidade. Esse paradigma vem se apresentando como o

${ }^{1}$ Dados relacionados à produção do Vestuário, em Geral, Meias, Linha Lar e Artigos Técnicos. 
principal gerador de problemas ambientais graves e torná-lo responsável é pensá-lo em harmonia com o futuro, é pensar em um desenvolvimento voltado à responsabilidade e à solidariedade do presente para com o planeta futuro (KAZAZIAN, 2005).

Assim, este estudo tem como objetivo propor procedimentos para desenvolvimento de produtos sustentáveis têxteis a partir de sobras de materiais das micro e pequenas confecções.

\subsection{JUSTIFICATIVA}

A sociedade sempre teve disponível toda estrutura natural e ambiental e nunca foi privada de utilizar o que o meio-ambiente tem para oferecer, mas o mau uso desses recursos, a ambição humana e o consumismo desenfreado acabaram mudando esse cenário. Mesmo sendo parte da natureza, o homem age muitas vezes sem consciência e não pensa no futuro e nos limites do ecossistema, o que já o fez ultrapassar os limites de quase tudo o que podia utilizar e ainda assim explora sem conscientização.

O homem e suas atitudes estão ferindo sua própria origem e exterminando seu futuro. O problema existe e a consciência sobre o mesmo está mais clara na mente de algumas pessoas que começaram a perceber e a se interessar pelo assunto, e a se posicionar, tomando atitudes em pequenas ou grandes iniciativas, em favor do meio ambiente.

Para Lipovetsky (1987), a sociedade de consumo é a programação do cotidiano: ela manipula e quadricula racionalmente a vida individual e social em todos os seus interstícios; tudo se torna artifício e ilusão a serviço do lucro capitalista e das classes dominantes.

Focado na obtenção do lucro, os empresários esquecem ou desconsideram alguns fatores de preservação. Mas, devido à preocupação mundial em meio às mudanças climáticas abruptas, ao derretimento das calotas polares e a outros fenômenos naturais excepcionais, a atenção para o resultado da industrialização e sobre a natureza começou a ganhar evidência devido à magnitude dessas ocorrências. Em contrapartida, as empresas podem contribuir, oferecendo produtos e serviços com qualidade, respondendo a expectativas, desejos e necessidades dos consumidores e contribuindo para o desenvolvimento econômico e social de sua região e de seu país. 
Segundo Popcorn (1997), uma das tendências para o futuro seria a do consumidor vigilante, o qual é alerta, disposto a proteger seus interesses e que não tolera deslizes por parte da empresa. Esse consumidor busca e reconhece seus direitos. Essa tendência em ascensão levará as empresas, a cada dia mais, buscar por melhorias e diferenciais para manter seus atuais clientes, bem como atingir potenciais clientes.

Neste contexto, o presente trabalho propõe procedimentos, utilizando como referência a metodologia de Löbach, para o desenvolvimento de produtos sustentáveis têxteis obtidos a partir de sobras de materiais de confecções.

\section{REVISÃO BIBLIOGRÁFICA}

\subsection{Breve histórico da indústria têxtil brasileira}

Ao contextualizar o histórico da Cadeia Têxtil no Brasil, é válido dividi-lo em três fases subsequentes: na primeira fase, desde a origem da cadeia até o ano de 1965, é relevante o fato de que a fabricação dos produtos têxteis precede a chegada da família portuguesa em solos brasileiros, mas com falta de registros contundentes, leva-se em consideração o início estagnado do processo em 1500 até 1844, pois, segundo Sinditêxtil (2007), os fatos marcantes dessa fase estão relacionados à montagem de uma economia colonial complementar, a qual absorvia as matérias-primas existentes e não visava à transformação das mesmas em produtos industrializados. A manufatura têxtil foi proibida, sendo permitida apenas a produção de "panos grosseiros" para os escravos. Somente após esse período até 1913 pode-se considerar a efetividade da implantação desse processo.

Segundo Monteiro Filha e Correia (2003), a partir de 1864 com o crescimento da cultura algodoeira, a mão de obra em excesso, o mercado consumidor em crescimento, a Guerra Civil Americana, a Guerra do Paraguai e a abolição da escravatura, houve a inevitável ascensão industrial, resultando na maior disponibilidade dos capitais antes empregados no ramo negreiro. Às vésperas da Primeira Guerra Mundial, havia duzentas fábricas, que empregavam 78 mil pessoas. A guerra pode ser considerada fator decisivo na consolidação da indústria têxtil brasileira. Naquele ano, estariam funcionando no país vinte fábricas, com cerca de 15 mil fusos e 385 teares. Em 1881, o parque têxtil possuía 44 fábricas e 60 mil fusos, gerando cerca de 5 mil empregos. 
Suzigan (1986) enfatiza que "o desenvolvimento da indústria têxtil de algodão se deu principalmente a partir de fins da década de 1860. Os principais surtos de investimento nessa indústria ocorreram nos seguintes períodos: entre fins da década de 1860 e meados de 1870; na década de 1880 e início de 1890; no período de 1907 a 2013; na década de 20 (particularmente entre 1924 a 1926); e na década de 30, especialmente a partir de 1933".

Monteiro Filha e Correia (2003) ressaltam que, na década de 1920, houve o surgimento das importações, as quais foram reduzidas com a crise de 1929. A oportunidade de crescimento só voltaria com a Segunda Guerra Mundial: no período entre guerras, a participação do setor no produto industrial era de $23 \%$.

Celso Furtado (1957) indicava que países que constituíam os grandes mercados importadores de tecidos de algodão (países subdesenvolvidos) começaram a instalar importantes centros fabris têxteis a partir do primeiro conflito mundial. Muitos desses países eram produtores de algodão e intensificaram a produção para atender às necessidades da indústria nacional.

A segunda fase, que abrange o período de 1965 a 1989, teve como característica a intensificação do investimento no setor; a partir de 1970, a delonga ocorreu, devido à descomedida ociosidade e o alto índice de obsolência no parque fabril, tanto na cultura algodoeira quanto nas fibras sintéticas.

Após o choque do petróleo, em 1973, o setor atravessou forte crise nos anos seguintes. Em 1975, as indústrias de fiação de seda japonesas operaram com alta ociosidade, uma vez que não tinham condições de exportar para o Japão (seu maior importador).

Em 1970, a indústria têxtil empregava $13 \%$ do pessoal da indústria de transformação. Em 1975, esse percentual caiu para 9\%. Na segunda metade da década de 1970, os grandes projetos se concentraram no Nordeste e iniciou-se um grande processo de substituição de equipamentos têxteis importados por nacionais (MONTEIRO FILHA E CORREIA, 2003).

Segundo o autor, em 1980, após a implantação das indústrias de base ${ }^{2}$ e de bens de capital, a indústria têxtil passou a ser responsável por apenas, 8,5\% da mão de obra

\footnotetext{
${ }^{2}$ Indústrias de base: Também conhecidas como indústrias pesadas, são aquelas voltadas para a produção de equipamentos (indústrias de bens de capital) e matérias-primas processadas (indústrias extrativas) para
} 
empregada na indústria de transformação. A partir do segundo semestre de 1984, o setor têxtil apresentou sinais de recuperação, consolidando-se em 1985.

Em 1990, com a abertura comercial, as tarifas de importação de tecidos passaram de $70 \%$ para $40 \%$. Logo depois, a alíquota caiu para $18 \%$, afetando as tecelagens, tinturarias, estamparias e até as fiações. O consumo dos fios sintéticos e artificiais apresentou rápido crescimento entre os anos de1990 e 2001 e teve crescimento moderado no período de 1995 a 1999, ou seja, gradativamente vem substituindo os naturais.

Atualmente, o valor da produção da cadeia têxtil e de confecção representa o equivalente a pouco mais de 5,7\% do PIB total brasileiro e de $17 \%$ da indústria de transformação. Esse segmento emprega cerca de 1,6 bilhões de trabalhadores, o que representa $16,4 \%$ do total dos trabalhadores alocados na indústria da transformação (IEMI 2014).

\subsection{Breve histórico do setor do vestuário no Brasil}

O setor do vestuário no Brasil teve sua formação industrial na primeira metade do século XX. Segundo Kontic (2002), na década de 1920, o vestuário já era o terceiro maior setor industrial no Brasil. Apesar disso, até a década de 1950, sua composição era de pequenas oficinas "semiartesanais" de costura e de costureiras autônomas que confeccionavam suas roupas em suas casas.

Nas décadas de 50 e 60, surgiram novos padrões de consumo. Devido ao crescimento econômico, houve o aumento da produtividade, disseminando, assim, o processo de terceirização. Em contrapartida, o aumento da demanda por produtos básicos, gerado pelo consumo urbano em massa, favoreceu o foco na produção em escala (KONTIC, 2002).

O auge da concentração industrial do setor ocorreu no fim da década de 1970: em 1980, 44\% do emprego paulista no vestuário se concentrava em empresas com mais de 100 empregados (KONTIC, 2002).

Segundo Kontic (1981), na década de 1980 ocorreu um grande atraso em relação ao acesso à capacitação tecnológica, à falta de mecanismos de difusão, ao pouco

outras indústrias. Exemplos de indústrias de base de bens de capital: siderúrgicas, metalúrgicas, indústrias de equipamentos e máquinas Piquet (2007). 
investimento e interesse ao setor, e às inovações tecnológicas. Por conseguinte, o caminho a ser traçado, visando à redução de custos, foi a terceirização da mão de obra, ainda que deixando de levar em conta as obrigações trabalhistas e tributárias.

A produção da moda brasileira passou por grandes transformações desde a abertura comercial, auxiliada com medidas econômicas resultadas do Plano Real, ocasionando o aumento da competitividade e a criação de muitas empresas que geram produtos com ciclos de vida curtos, comercializados em uma variedade de formas varejistas em um amplo comércio especializado, os chamados Fast Fashion. Esse período foi marcado pela queda relativa de preços nos artigos do vestuário. Em contrapartida, a instabilidade afetava a indústria com sobras de produção, resultado da recessão brusca que gerou cancelamento e devolução de pedidos. Como alternativa, diversos fabricantes passaram a comercializar seus produtos em seus galpões, atraindo, assim, pequenas lojas de bairro, lojistas do interior, vendedores autônomos etc., que encontraram uma maneira de comercializar uma grande variedade de produtos, em diversos níveis de preços e qualidade, sem o risco de arcar com estoques desnecessários (CARVALHINHA, 2003).

\subsection{Economia verde e sustentabilidade}

\subsubsection{Economia verde}

Atualmente pode-se afirmar que a economia verde deixou de ser modismo para se tornar o meio necessário ao desenvolvimento sustentável. Segundo PNUMA ${ }^{3}$ (2011), economia verde é uma economia que resulta em melhoria do bem-estar da humanidade e igualdade social, ao mesmo tempo em que reduz significativamente riscos ambientais e escassez ecológica.

Desde a ECO 92, Conferência das Nações Unidas sobre o meio ambiente e desenvolvimento, realizada no ano de 1992, na cidade do Rio de Janeiro, acreditava-se que proteger florestas e o meio ambiente, realizar diversos projetos voltados à sustentabilidade, envolver a comunidade local e conscientizar publicamente a população

\footnotetext{
${ }^{3}$ PNUMA é a sigla em português do Programa das Nações Unidas para o Meio Ambiente (em inglês, United Nations Environment Programme - UNEP). Sediado em Nairóbi, no Quênia, o programa foi criado pelas Nações Unidas em 1972, atendendo a proposta da Conferência das Nações Unidas sobre o Meio Ambiente Humano, realizada naquele ano em Estocolmo, na Suécia. Tem como missão liderar e encorajar parcerias ambientais, inspirando, informando e preparando povos e nações para melhorar sua qualidade de vida, sem prejudicar a das gerações futuras.
} 
seria o suficiente para se obter um planeta sustentável, ou seja, viver em um planeta harmonioso no qual todos os habitantes pudessem se alimentar, tivessem qualidade de vida e se integrassem com a natureza de forma harmoniosa.

Segundo Hamú (2011), essa equação é um sonho, já que muitos ambientalistas trabalham fundamentados na utopia baseada nos mercados globalizados, nos interesses políticos e na forma com a qual o ser humano vive e se desenvolve. Alguns estudos afirmam que, em várias partes do mundo, a produção voltada ao consumo chega a ser equivalente aos gastos de recursos de três planetas; já em outras partes, os países não conseguem consumir nem o equivalente a $0,1 \%$ de recursos, pois sua população vive em extrema pobreza.

A economia verde surgiu com o intuito de trazer os elementos econômicos do mercado para o meio ambiente, permitindo, assim, a equalização do desenvolvimento sustentável, ou seja, atender às necessidades de todos no presente, sem comprometer a capacidade das gerações futuras. Em momento algum impõem-se que a população detentora da riqueza se permita deixar de ser rica, mas que, outrossim, haja uma justa distribuição de renda com um tipo de economia que atue de forma inclusiva, trabalhando com a produção mais sustentável, gerando benefícios para a sociedade. Outra vantagem é a criação de empregos verdes que poderão dar origem a novas profissões, voltadas para o trabalho sustentável e para a remuneração mais justa.

Segundo PNUMA (2011), o conceito de economia verde não substitui o desenvolvimento sustentável. Hoje em dia existe um crescente reconhecimento de que a realização da sustentabilidade se baseia quase que inteiramente na obtenção do modelo certo de economia. A sociedade atual se preocupou com a criação da riqueza através de um modelo de "economia marrom", que utiliza vários recursos naturais, de forma inconsciente, por acreditar serem inesgotáveis, ao mesmo tempo em que não soube lidar de modo substancial com a marginalização social e o esgotamento de recursos. Por isso, acredita-se que ainda está longe de atingir os objetivos de desenvolvimento do milênio. Contudo, se todos não se conscientizarem do valor de movimentos que pregam a reversão dessa situação, a população não vai conseguir superar as diferenças sociais e econômicas e as empresas vão perder seus capitais naturais gerando a escassez da matéria-prima para a produção. 


\subsubsection{Sustentabilidade}

Segundo a Organização das Nações Unidas, relatório Brundland (1987), “desenvolvimento sustentável é aquele que atende as necessidades das gerações atuais sem comprometer a capacidade das gerações futuras de atenderem a suas necessidades e aspirações". Atualmente, essa definição não atende a todo contexto relacionado ao termo, pois devem ser levados em consideração não só o ser humano, mas também todos os outros seres vivos que necessitam da biosfera e da sustentabilidade.

O termo em si está relacionado ao desafio da sobrevivência devido às consequências trazidas pela exagerada transformação dos elementos naturais executada pelo homem.

Segundo Almeida (2002), no mundo atual, a percepção de que tudo afeta a todos, cada vez com maior intensidade e menor tempo para absorção, gerou o processo de redefinição, conceitual e pragmático, e levou à formulação do conceito de desenvolvimento sustentável. Porém essa base conceitual é de difícil implementação: tanto o governo quanto as empresas devem levar em consideração as dimensões ambientais, econômicas e sociais.

Segundo Kraemer (2005), o desenvolvimento econômico e o meio ambiente estão intimamente ligados. Só é válida a utilização dos recursos naturais para contextos em que haja consciência e responsabilidade no uso dos recursos escolhidos, pois, se algo falhar no meio do processo, a degradação e o agravamento da situação se tornam inevitáveis. Como demonstra a figura 1, a busca pelo desenvolvimento sustentável deve obedecer a três critérios fundamentais simultaneamente: equidade social, prudência ecológica e eficiência econômica. 
Figura 1 - Desenvolvimento Sustentável - Tripé da sustentabilidade empresarial Desenvolvimento Sustentável - Tripé da sustentabilidade empresarial

- proteçăo ambiental

- recursos renováveis

- ecoeficiência

- gestāo de resíduos

- gestáo dos riscos

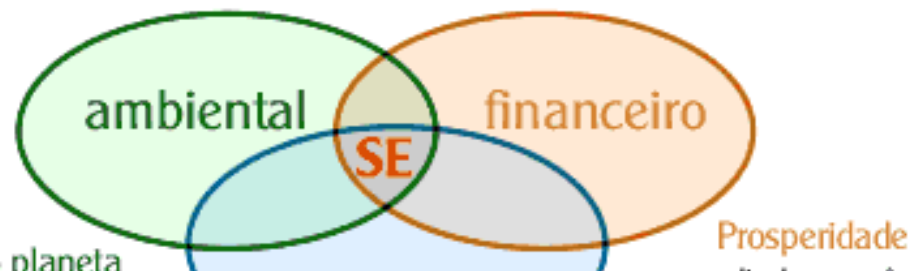

- resultado econômco

- direitos dos acionistas

- competitividade

Dignidade Humana

- relação entre clientes

- direitos humanos $e$ fornecedores

- direitos dos trabalhadores

- envolvimento com comunidade

- transparência

- postura ética

$\mathrm{SE}=$ Sustentabilidade Empresarial

Fonte: Kraemer (2005)

Segundo Almeida (2002), para a colocação desse conceito em prática, devem-se observar os seguintes pré-requisitos: democracia e estabilidade política; paz; respeito à lei e à propriedade; respeito aos instrumentos de mercado; ausência de corrupção; transparência e previsibilidade de governos e reversão do atual quadro de concentração de renda em esfera local e global.

\subsection{Meio ambiente e o setor da confecção}

A expectativa da sociedade está voltada à melhoria das condições de vida. Neste enfoque, as pressões sociais sobre as empresas estão cada vez mais fortes, de tal forma que modificam o comportamento delas e, muitas vezes, determinam sua extinção.

Segundo Andres (2001), a demarcação do nível de poluição socialmente aceitável está diretamente relacionada ao nível de incômodo que a sociedade está disposta a suportar e, sobretudo, qual a contrapartida de recursos de que está disposta a abrir mão para melhorar o seu meio ambiente. As preferências têm variação entre regiões, crenças, classes sociais, culturas e ideologias.

Dentro dessa ótica, as organizações podem agir de forma proativa, reduzindo a quantidade de material usado nos produtos e serviços, o consumo e o custo de energia, 
criando novos produtos e serviços para novas oportunidades de mercado, de forma a possibilitar a redução dos riscos ambientais, aplicando e adquirindo tecnologias novas, bem como melhorando de forma geral a imagem pública da empresa.

Segundo Agis, Bessa, Gouveia e Vaz (2010), como o mercado da moda está sempre em busca de melhorias contínuas e formas de inovação dos seus produtos, não houve resistência alguma em passar pela rápida mutação do mercado e criar um novo negócio: a moda sustentável. Se na Alta Costura do começo do século XX o luxo se manifesta pelo uso de materiais caros e exclusivos, o novo luxo de hoje se caracteriza por consumir a moda de uma maneira consciente, feita com produtos reciclados ou pensados a partir de uma proposta do ecodesign.

A indústria da moda sempre esteve entre as indústrias que emitem grande quantidade de resíduos ambientais. As sobras de tecidos provenientes das atividades de corte, as águas residuais procedentes das atividades de lavagem e acabamentos de tecidos se constituem em agentes impactantes ao meio ambiente. Dessa forma, o processo de produção do vestuário que ocorre ao longo da cadeia produtiva está relacionado intimamente com as variáveis ambientais e podem gerar altos impactos ambientais nos vários elos dessa cadeia produtiva.

Entende-se por ecodesign todo processo que contempla os aspectos ambientais em todos os estágios de desenvolvimento de um produto, colaborando para reduzir o impacto ambiental durante seu ciclo de vida. A definição de ecodesign proposta por Fiksel (1996) diz que o projeto para o meio ambiente é a consideração sistemática do desempenho do projeto, com respeito aos objetivos ambientais, de saúde e segurança, ao longo de todo o ciclo de vida de um produto ou processo, tornando-o ecoeficiente, o que leva à produtividade e lucratividade.

Segundo Barros (2011), a moda verde baseada nos conceitos do ecodesign é o novo luxo do século XXI, opondo-se ao consumismo desenfreado típico da era do consumo. Os produtos relacionados ao mercado têxtil e vestuário a serem desenvolvidos, baseados no ecodesign, deverão buscar na sustentabilidade um de seus diferenciais em relação às opções existentes no mercado. A sustentabilidade é entendida aqui como a manutenção dos recursos atuais para as gerações futuras, podendo ser dividida em três vértices (VEZZOLI; MANZINI, 2002):

a) a questão ambiental: que tem como características a escolha de materiais 
renováveis, a utilização de refugos de produção, entre outros;

b) a questão socioética: que prevê a melhora no convívio entre os indivíduos, a multipolarização da sociedade e soluções através das quais o indivíduo exercita da melhor maneira possível as suas capacidades;

c) a questão econômica: é fundamental a geração de emprego e renda através das soluções sustentáveis, sob pena de as outras dimensões da sustentabilidade não perdurarem.

Mello (2012) descreve os fatores impulsionadores que devem ser observados no desenvolvimento de produtos sustentáveis:

a) consciência de mercado: melhoria da consciência ambiental dos clientes industriais e do varejo sobre o desempenho ambiental dos produtos;

b) diferenciação: projetos ecoeficientes são superiores em termos de elegância, conservação de energia e custo, e podem balançar uma decisão de compra, se o preço e o desempenho forem compatíveis;

c) redução de custo: contribuições na rentabilidade da linha de produto por meio de ganhos em produção, distribuição e outros custos ligados ao ciclo de vida;

d) programas de selos ecológicos;

e) pressões regulatórias: cada vez mais restritivas, especialmente em relação à disposição e reciclagem dos desperdícios;

f) padrões internacionais: TC 207 da ISO - Norma ISO TR 14062 / ABNT 14062 Gestão ambiental - integração de aspectos ambientais no projeto e desenvolvimento do produto.

\subsection{Desenvolvimento de produtos e metodologias de projeto}

O desenvolvimento de produtos trata de questões relevantes para a maioria das organizações, principalmente as manufatureiras. A busca pela competitividade e a sustentabilidade do negócio fazem com que o desenvolvimento de produtos seja contemplado nos planos estratégicos das organizações que buscam se diferenciar por produtos e serviços inovadores (CHUM, 2010).

O desenvolvimento de produtos teve seu início após a I Guerra Mundial, quando a produção em massa se apresentava como uma evolução da produção artesanal. Tinha como princípios: divisão de tarefas, especialização dos funcionários e busca pela melhor 
maneira de executar as atividades. Com o passar dos tempos, essa função recebeu o nome de desenvolvimento de produtos sequencial ou engenharia tradicional, cujo processo se iniciava no marketing, passando pelo desing, produção até seu destino final.

Conforme Rozenfeld et al. (2006), o desenvolvimento de produtos na sua visão tradicional apresentava diversas deficiências, entre elas, a falta de comunicação e integração dos setores da empresa, dificultando a busca pela solução dos problemas que surgiam durante o processo de fabricação.

No início da produção em massa, essas deficiências não eram tão prejudiciais como agora, pois o ciclo de vida dos produtos era maior, o produto ficava mais tempo no mercado e a concorrência era menor.

Com o aumento da velocidade da informação, desenvolvimento de novas tecnologias, concorrência acirrada e clientes que buscavam produtos com qualidade e preço acessível, houve necessidade de melhorar a eficiência do desenvolvimento de produtos. No início da década de 1960, surgiram as metodologias de projetos, com o objetivo de propor uma sequência lógica de etapas para o desenvolvimento de produtos.

Segundo Freitas et al. (2010), a metodologia projetual pode ser definida como sendo um conjunto de procedimentos para o desenvolvimento de um determinado produto, onde estão relacionados: os métodos, ou seja, caminho pelo qual se atinge um objetivo; as técnicas, como habilidade para execução de determinada ação ou produtos; e as ferramentas, como instrumentos ou utensílios empregados no cumprimento dessa ação.

Existem diversas metodologias para o desenvolvimento de produtos, onde cada autor expõe uma proposta para elaboração de produtos. Conforme a complexidade, o objetivo final e a sua área de atuação, todas têm como objetivo solucionar um problema de design que atenda ou vá além da necessidade do cliente (MELLO, 2011). A análise das metodologias existentes na literatura irá auxiliar tanto na elaboração de um novo modelo como na adaptação de um modelo existente.

\subsubsection{Metodologia de Löbach}

Löbach (2001) define o design como um processo de comunicação de que fazem parte quatro elementos: o designer que desenvolve o produto; a empresa que produz o produto; o usuário do produto; e o objeto de design que é o produto industrial. Todo o 
processo de design é tanto um processo criativo como um processo de solução de problemas concretizado em um projeto industrial e incorpora as características que possam satisfazer às necessidades humanas de forma duradoura. Dependendo da magnitude do problema, o processo se desenvolve de forma extremamente complexa, e pode ser dividido em quatro fases distintas: análise do problema, geração de alternativas, avaliação das alternativas e realização da solução do problema. Embora nunca sejam separáveis no caso real, elas se entrelaçam umas às outras com avanços e retrocessos durante o processo de projeto (MELLO, 2011).

Segundo Löbach (1981), todo processo de design é criativo como um processo de solução de problemas, em que um problema existe e é descoberto. Para isto, se coletam informações sobre o problema, se desenvolvem soluções e estas se avaliam segundo critérios estabelecidos, para, finalmente, se desenvolver a solução mais adequada. Dessa forma, o modelo, além de ser prescritivo, é descritivo.

\section{METODOLOGIA PROPOSTA}

Foram selecionadas duas empresas para testar a validade do modelo proposto: a empresa A, fabricante de vestes litúrgicas e a empresa B, fabricante de jalecos para médicos.

A empresa A, única no Brasil, possui dez funcionários, que se dedicam aos preceitos do catolicismo, pois, como a empresa produz vestes sagradas, então, o operador sempre executa sua função rezando por aquele que vai utilizar a vestimenta. $O$ mix de produtos desta empresa está subdividido em: casulas, estolas, túnicas e vestes. Esta empresa fabrica os seus produtos sob encomenda, e as sobras de confecção eram desprezadas, gerando acúmulo de resíduos.

A empresa $\mathrm{B}$, possui dois funcionários e produz peças que sejam úteis aos seus clientes, agregando valor com design, estampas diferenciadas e informação de moda. Esta empresa usa como matéria-prima tecidos na cor branca, $100 \%$ poliéster, com acabamento de nitrato de prata. As sobras de tecidos desta empresa também eram desprezadas, gerando um acúmulo de resíduos.

A empresa B tem participado de eventos, feiras e festivais voltados ao desenvolvimento sustentável. Um exemplo é o trabalho que vem desenvolvendo com a Associação VER (Voluntários Emilio Ribas), onde os desenhos feitos pelos pacientes 
internados são fotografados e estampados nos nécessaires para serem comercializados em bazares. O processo de produção dos produtos é feito de forma simples, utilizando apenas as máquinas de corte, costura reta e overloque.

O problema a ser resolvido é reduzir os resíduos (sobras de confecção) das duas empresas e o excesso de matérias-primas em estoque da empresa A. As sobras de tecidos da empresa A ocorrem em função do tipo de produto fabricado por esta empresa (modelos personalizados) e o excesso de tecidos em estoque é devido às novas ordens provindas do Vaticano que desautorizam o uso de determinados tipos de tecido na fabricação das vestimentas. Na empresa B, sobram tecidos brancos.

O desafio deste estudo é prolongar a vida útil da matéria-prima utilizada na confecção das peças, já que em muitos lugares a mesma é totalmente descartada em lixões.

Primeiramente, foi montada uma matriz para analisar os princípios de sustentabilidade praticados pelas empresas.

\subsection{Análise da matriz da avaliação das empresas, segundo critérios básicos de sustentabilidade}

Foi montado um instrumento com 33 questões, que foram respondidas pelos gestores das empresas, para verificar a sustentabilidade ambiental das duas empresas, visando a quantificar algumas ferramentas que auxiliam na transição da economia atual, como a ecoeficiência, produção mais limpa e análise do ciclo de vida. Para a análise, utilizou-se como instrumento de pesquisa o Sistema Contábil Gerencial Ambiental (SICOGEA), adaptado pela pesquisadora de Uhlmann (2011). Ressalta-se que foi utilizada nesta pesquisa somente a fase um da terceira etapa do SICOGEA - Geração 3. As respostas foram ponderadas, de forma ordinal qualitativa, de 0 (zero) a 5 (cinco) pontos, conforme sugerido por Nunes (2010) e Uhlmann (2011), ou seja:

a) Não se aplica: para a questão que não demonstra nenhuma relação sobre o item avaliado. Neste caso, a pontuação da resposta equivale a 0 (zero) ponto.

b) Não atende: não demonstra algum investimento/controle sobre o item avaliado. Neste caso, a pontuação da resposta equivale a 1 (um) ponto.

c) Atende parcialmente: demonstra investimento/controle mediano sobre o item avaliado. Neste caso, a pontuação da reposta equivale a 3 (três) pontos. 
d) Atende: demonstra investimento/controle total sobre o item avaliado. Neste caso, a pontuação da resposta equivale a 05 (cinco) pontos.

Para a obtenção do grau de sustentabilidade somou-se a pontuação obtida em cada questão, que podia variar de 0 a 165 pontos, delimitados pela pesquisadora, o que resultou no total dos pontos alcançados em cada questão. O gráfico 1 mostra o total de pontos de cada empresa.

Gráfico 1: Avaliação das empresas segundo critérios básicos de sustentabilidade

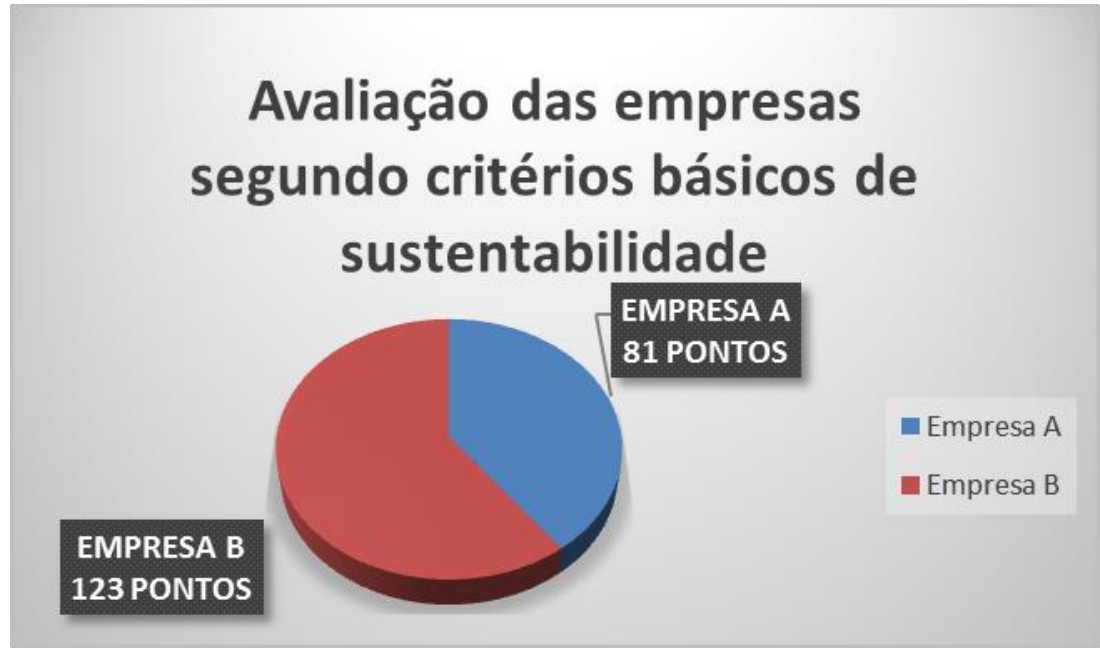

Fonte: Fernanda Marinho (2015)

A avaliação da sustentabilidade e desempenho ambiental das empresas foi feita utilizando-se a tabela 1 .

Tabela 1 - Avaliação da sustentabilidade e desempenho ambiental segundo o SICOGEA - Geração 3

\begin{tabular}{|c|c|c|}
\hline Resultado & Sustentabilidade & Desempenho: controle, incentivo e estratégia \\
\hline Zero ponto & Péssima - 'P' & Causa grande impacto ao meio ambiente. \\
\hline Entre 1 a 33 pontos & Fraca - 'F' & $\begin{array}{c}\text { Pode estar causando danos, mas surgem } \\
\text { algumas poucas iniciativas. }\end{array}$ \\
\hline Entre 34 a 99 pontos & Regular - 'R' & Atende somente à legislação. \\
\hline
\end{tabular}


\begin{tabular}{c|c|c} 
& & Alta valorização ambiental com produção \\
Entre 100 e 165 pontos & Ótima - 'O' & ecológica.
\end{tabular}

Fonte: Pfitscher (2004); Nunes (2010); Uhlmann (2011) adaptada por Silva (2015)

A empresa A obteve 81 pontos na pontuação geral e a empresa B 123 pontos. $\mathrm{O}$ resultado apresentado, de acordo com a avaliação aplicada, considerou que a empresa A está no padrão regular da sustentabilidade enquanto a empresa B se encontra no padrão ótimo, mas, observando a matriz, percebe-se que ainda existem planos a serem traçados para sua melhoria.

A diferença é, realmente, notória visto que, apesar de as duas empresas serem do mesmo ramo de atuação, trabalham com segmentos e objetivos distintos, conforme segue:

A empresa A atua em um segmento padronizado e não levava em consideração o quanto era nocivo produzir peças com fibras sintéticas. Sua produção, praticamente artesanal, não tinha a preocupação em coletar e analisar dados de desempenho, existia apenas a preocupação do estoque obsoleto, formado a partir das ordens provindas do Vaticano que desautorizam o uso de muitos tecidos que esta empresa possui em seu estoque de matérias-primas. Assim, o mesmo estoque, além de obsoleto, se tornou inviável, indicando a necessidade de encontrar outro nicho de mercado para a utilização do mesmo. A preocupação com a qualidade de vida de seus funcionários é seu diferencial e pode ser observada através da conscientização do desperdício de energia e água, que sempre atinge a meta estipulada.

A empresa B trabalha na direção oposta, trabalha com banners já utilizados e resíduos para produzir itens que não possuam a necessidade de lavagem contínua. Desde a sua criação até os dias atuais, sua preocupação com o meio ambiente é latente tanto que, para a limpeza do banner, utiliza, apenas, 1 (um) litro de água com gotas de vinagre, com o maior aproveitamento possível do material, e o que não pode ser utilizado é enviado à coleta seletiva. $\mathrm{O}$ que foi diagnosticado como preocupante é o fato de, por se tratar de uma confecção com 2 funcionários, é impossível o controle em relação ao manuseio dos produtos nas oficinas externas e, por trabalhar constantemente 
em feiras e eventos, contribui com a emissão de gás carbônico através da locomoção dos produtos e funcionários com seu veículo.

\subsection{Desenvolvimento do projeto conceitual}

Segundo Löbach (2001, p.141) "todo o processo de design é tanto um processo criativo como um processo de solução de problemas."

A metodologia de Löbach (1976) deixa explícito, em uma das etapas, que o designer deve pensar nas relações sociais do processo em desenvolvimento e enfatiza a função estética e simbólica do produto. Com relação às questões sociais, o método traz, na fase de preparação, a análise da relação social. Segundo Löbach (2000), as "[...] relações do provável usuário com o produto planejado: que classes sociais o utilizariam e ainda se a solução é adequada para proporcionar prestígio social, i.c., servir de símbolo [...]", esses itens devem ser avaliados durante todo o processo.

Não se pode afirmar que os outros autores não tinham preocupação com essas questões, porém nenhum deles as explicitou de forma clara e concisa e por isso não estavam caracterizadas nas descrições dos métodos que desenvolveram.

Como as questões relacionadas ao design social são muito importante para o desenvolvimento desta pesquisa, a pesquisadora optou por utilizar como referência a metodologia proposta por Löbach.

A metodologia proposta por Löbach (1976) é dividida em quatro etapas: a fase de preparação, quando são coletadas e analisadas todas as informações pertinentes; a fase de geração, quando alternativas são propostas com base no conhecimento acumulado; a fase de avaliação das soluções encontradas; e a fase de realização da alternativa escolhida.

A tabela 2 mostra os procedimentos realizados para o desenvolvimento de um produto sustentável, fabricado a partir dos resíduos gerados pelas confecções em estudo.

Tabela 2: Etapas seguidas, adaptadas da metodologia de Löbach, para o desenvolvimento dos produtos sustentáveis, fabricados a partir dos resíduos gerados pelas confecções. 


\begin{tabular}{|c|c|c|}
\hline $\begin{array}{l}\text { Processo } \\
\text { Criativo }\end{array}$ & Processo de solução de Problema & Processo de design (descrição de produto) \\
\hline $\begin{array}{c}\text { Etapa } 1 \\
\text { Preparação }\end{array}$ & $\begin{array}{l}\text { Análise do Problema. } \\
\text { Coleta de informações. } \\
\text { Análise das informações. } \\
\text { Definição de objetivos. }\end{array}$ & $\begin{array}{l}\text { Foram coletadas e analisadas informações que deram } \\
\text { subsídio às decisões tomadas no decorrer do processo. } \\
\text { Foram detectadas as necessidades da empresa A: } \\
\text { diminuição do estoque de matérias-primas e utilização } \\
\text { das sobras de confecção. } \\
\text { Foram estudas as oportunidades que puderam ser } \\
\text { transformadas em problemas de design. } \\
\text { Foram definidos os objetivos. }\end{array}$ \\
\hline $\begin{array}{c}\text { Etapa } 2 \\
\text { Geração }\end{array}$ & $\begin{array}{l}\text { Alternativa do problema. } \\
\text { Escolha do método para solucionar } \\
\text { o problema. } \\
\text { Produção de ideias. } \\
\text { Geração de alternativa. }\end{array}$ & $\begin{array}{l}\text { Alternativas de solução: busca de uma empresa parceira. } \\
\text { Definição do público alvo. } \\
\text { Processo criativo em conjunto com a empresa parceira. } \\
\text { Foram sugeridos alguns possíveis produtos (esboço de } \\
\text { ideias, modelos). }\end{array}$ \\
\hline $\begin{array}{c}\text { Etapa } 3 \\
\text { Avaliação }\end{array}$ & $\begin{array}{l}\text { Avaliação / alternativas problema. } \\
\text { Exame das alternativas, seleção. } \\
\text { Processo de avaliação. }\end{array}$ & $\begin{array}{l}\text { Escolha da melhor solução. } \\
\text { Definição das características do novo produto. } \\
\text { Acompanhamento do processo da solução para } \\
\text { diagnosticar possíveis falhas do método escolhido. }\end{array}$ \\
\hline $\begin{array}{c}\text { Etapa } 4 \\
\text { Realização }\end{array}$ & Solução do Problema & $\begin{array}{l}\text { Diagnóstico da aceitação do produto para o público alvo. } \\
\text { Detalhamento do produto desenvolvido. } \\
\text { Desenvolvimento dos modelos. } \\
\text { Elaboração da ficha técnica, ficha de corte, sequência } \\
\text { operacional e ficha de controle de qualidade. } \\
\text { Elaboração da documentação de todas as etapas } \\
\text { realizadas, desde a preparação até a produção do produto } \\
\text { final. }\end{array}$ \\
\hline
\end{tabular}

Fonte: Adaptada de Löbach (2001)

\subsubsection{Etapa de preparação}

Nesta etapa, foram realizadas quatro visitas à fabrica, em Cabreúva, foram coletadas e a analisadas informações sobre empresa A e detectadas as necessidades da mesma, para formular os problemas de design que deram origem às ideias para a fabricação de novos produtos.

\subsubsection{Etapa de geração}


O maior problema a ser resolvido na empresa A foi diagnosticado como sendo o estoque obsoleto das matérias-primas, seguido pelas sobras de confecção que eram desprezadas, gerando acúmulo de resíduos. A empresa não teve interesse em diversificar a sua linha de produtos, os gestores optaram por buscar no mercado uma empresa parceira (empresa B) para a fabricação dos novos produtos. Ficou definido que o público alvo seriam os romeiros católicos clientes da "loja da fábrica" mantida pela empresa A. Todo o processo criativo foi realizado em conjunto com a empresa B. Foram sugeridos alguns produtos.

\subsubsection{Etapa de avaliação}

Para a fabricação dos protótipos foram escolhidos tecidos brocados roxos e o Oxford creme da empresa A, um banner, doado pelo Auditório do Ibirapuera, uma lona, doada por uma empresa de estofados, o tecido do forro de poliéster que foi doado por uma empresa especializada em produzir uniformes e o tecido estampado por sublimação da empresa B. Apenas os aviamentos (zíper, viés, linha mista, alça pronta) que foram compradas em lojas do ramo. A Figura 2 mostra o processo da construção do protótipo. 
Figura 2: Etapas do processo de fabricação do protótipo

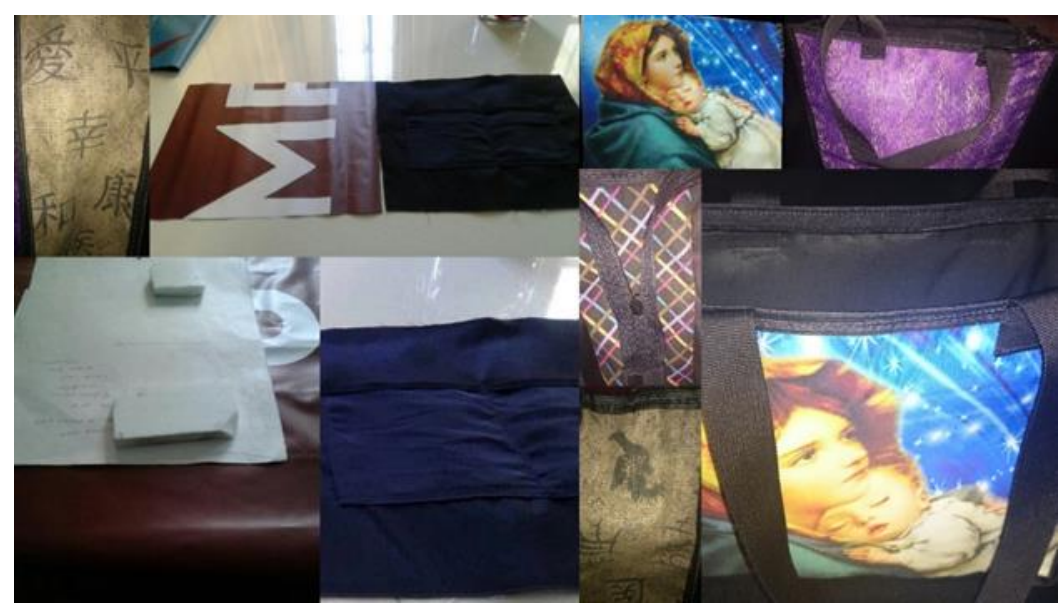

Fonte: Maria Venuíra Bernal Cano (2015)

\subsubsection{Etapa de realização}

Uma vez que o objetivo desta pesquisa foi propor procedimentos para o desenvolvimento de produtos sustentáveis têxteis, entendeu-se que, para a etapa de realização, se fazia necessário registrar as ações por parte dos atuantes na fábrica, a fim de proporcionar maior controle e minimizar os transtornos que podem ocorrer resultantes de falhas na comunicação entre uma etapa fabril e outra.

Os registros de controle utilizados nas confecções brasileiras, ficha técnica, ficha da sequência operacional, foram, nesta pesquisa, também os utilizados no processo de fabricação do produto.

\section{CONCLUSÃO}

É notória a percepção do mundo atual com as questões ambientais, sociais e econômicas, visto que o recurso natural está mais escasso e raro e isso também abrange o segmento do vestuário cujo quadro, segundo Pimentel (2015), está complicado desde a crise de 2008, devido ao processo recessivo mundial, não existindo ainda previsão concreta de melhorias. O caminho para superação seria uma sociedade que evolua e tenha mais bem-estar consciente. Para isso, o setor têxtil e de confecção tem grandes chances e capacidade, pois denota o aspecto criativo da indústria a qual atrai a mídia e eventos, contudo tem que haver um crescimento nos materiais, modelagem, design e cadeia de produção. Pimentel ainda afirmou que, para sobrevivência da cadeia têxtil e 
vestuário, o Brasil deve voltar toda a atenção aos quesitos da sustentabilidade, pegadas de carbono, pegadas de água, pois a relevância da governança ética vem crescendo a cada momento.

O foco principal da pesquisa foi trabalhar a necessidade - que cabe às pessoas de criar soluções que não sejam radicais, para promover o desenvolvimento e prosperidade da sociedade, sem agredir os sistemas naturais.

A geração de resíduos têxteis constitui-se em um fator relevante a ser tratado por qualquer indústria de confecção do vestuário, pois os desperdícios interferem na composição dos custos, na lucratividade e rentabilidade das empresas, além disso, impactam negativamente no meio ambiente.

De acordo com Jorge e Casagrande (2011), “nem sempre as preocupações com práticas sustentáveis estão firmemente implantadas nas organizações, podendo limitarse apenas ao atendimento da legislação a fỉm de evitar sanções fiscais". É o caso do resultado apresentado pela empresa A. Assim, tendo em vista a importância da gestão ambiental nas organizações de maneira a incentivar as práticas voltadas para esta área e as reduções dos impactos que podem estar sendo ocasionados por certas atividades, infere-se que deve haver investimento em maiores proporções, para ser reconhecida como socialmente responsáveis no mercado em que atua.

Em São Paulo, grande parte dos resíduos gerados é constituída por retalhos de malha, oriundos das empresas que atuam no segmento de Fast Fashion, nas composições $100 \%$ algodão, $100 \%$ fibras sintéticas, como poliéster, poliamida e elastano ou mistos.

Nesse contexto, alternativas sustentáveis surgem como possibilidades para o enfrentamento da conjuntura formatada pelos problemas ambientais. Sob este aspecto, a presente pesquisa demonstrou ser viável a possibilidade de desenvolvimento de novos produtos a partir do tecido existente no estoque das empresas e também a partir das sobras de confecções. Todavia, por se tratar de um público diferenciado, foi necessário avaliar a possibilidade de inserção desses produtos junto ao público consumidor, pois, este nível de interferência requer que as novas propostas sejam reconhecidas como válidas e socialmente aceitas. Não obstante, foi considerada a dificuldade em inserir produtos e serviços ecologicamente aceitáveis no âmbito de um quadro cultural e comportamental que continua dominado por expectativas e valores consumistas. 
Os produtos do vestuário desenvolvidos foram constituídos por bolsas, nécessaires e almofadas, sendo elaboradas através de Metodologia Projetual fundamentada por Löbach (2001) - devido a sua percepção em resolver problemáticas e pensar o desenvolvimento social - e pelos pressupostos de Sachs (2004) para tornar toda a metodologia eficiente em seu papel sustentável.

Sob este aspecto, o produto ecologicamente correto desenvolvido, durante o período de pesquisa, proporcionou novas experiências de consumo, traduzidas por meio de produtos criados a partir de temas que englobaram a cultura voltada ao catolicismo, na qual os consumidores estão inseridos. Esta ação configurou-se como um diferencial competitivo, destacando-se dentro de uma produção massificada, homogênea e globalizada, predominante na atualidade.

Assim, constatou-se que os produtos desenvolvidos a partir do reaproveitamento de banners, do estoque obsoleto da indústria de confecção e das sobras de confecções tiveram boa aceitação entre o público alvo, demonstrando o potencial de reaproveitamento de tais resíduos, o que é econômica e ambientalmente relevante.

Portanto, o resultado do Projeto serviu para medir o desempenho dos atributos dos produtos, bem como para promover uma reflexão em torno destes, a fim de proporcionar melhorias que estejam de acordo com os desejos dos consumidores. Como projeção futura, tem-se a ideia do aproveitamento da quantidade de viés presente no estoque da Empresa A e no desenvolvimento de novos produtos em conjunto com a Empresa B, pois desde o desenvolvimento desta pesquisa, se tornaram além de parceiros, geradores de um novo mix de produto para o mercado.

Destaca-se que os resultados apresentados nesta pesquisa ficam limitados às duas empresas analisadas, não podendo ser generalizado a outras. Todavia, pode ser usado como ponto de partida para efetuar um diagnóstico sobre a prática da gestão ambiental das micro e pequenas confecções.

\section{Artigo recebido em Julho de 2015. Aprovado em Maio de 2016 DOl:http://dx.doi.org/105965/1982615×09182016240}




\section{Referências}

ALMEIDA, F. O bom negócio da sustentabilidade. Rio de Janeiro: Nova Fronteira, 2002.

ANDRES, L. F. A Gestão Ambiental em Indústrias do Vale do Taquari: Vantagens com o uso das Técnicas de Produção Mais Limpa / Luiz Fernando Andres. Porto Alegre: UFRGS/PPGA, 2001.

As dimensões da Sustentabilidade. Disponível em: http://www.rumosustentavel.com.br/as-dimensoes-da-sustentabilidade/. Santa Catarina. 2011. Acesso em 08/06/2015

BARROS, I. S. O luxo do lixo: eco design uma nova perspectiva para a indústria da moda. Disponivel em: < http://www.antennaweb.com.br/edicao6/artigos/artigoeco.html> .Acesso em 01/06/2012.

BERLIM, L. Moda e sustentabilidade: Uma reflexão necessária. Estação das Cores e das Letras. São Paulo. 2012.

BNDES. Proposta de subprograma de ação setorial (SPI) - têxtil e vestuário. Rio de Janeiro, BNDES, 1978.

CARVALHINHA, M. P. O Setor do Vestuário: Uma análise sobre as possibilidades estratégicas das empresas do vestuário no Brasil. Dissertação (Mestrado) - Escola Politécnica da Universidade de São Paulo. 2006.

Centro Nacional de Tecnologias Limpas (CNTL). Manual de produção mais limpa. Porto Alegre: FIERGS, 1996.

CHUM, J. C. B. Gestão do processo de desenvolvimento de produtos e a gestão do ciclo de vida: proposta de um modelo para o desenvolvimento de produtos sustentáveis. Dissertação (Mestrado) - Universidade Federal do Rio de Janeiro. 2010. 
DIAS, R. Gestão Ambiental: Responsabilidade Social e Sustentabilidade. São Paulo: Atlas, 2006.

EL-KHOLY, O. A. Cleaner production. Arabian Gulf University, Manama, Bahrain. Encyclopedia of Global Environmental Change. John Wiley \& Sons, 2002. Disponívelem: <http://eu.wiley.com/legacy/wileychi/egec/pdf/GB604-W.PDF>. Acesso em: 20/06/2012

FIKSEL, J. Design for environment: Creating eco-eficiência products and processes, 1996.

FLETCHER, K. Sustainable fashions \& textiles: design journeys. Londres: Earthscan, 2010.

FREITAS, R. et al. Design Emocional e o designer como interpretador de desejos e necessidades: revisão de literatura. Revista Estudos em Design. PUC/RJ. Vol. 18. 2010.

GORINI, A. P. F. Panorama do setor têxtil no Brasil e no mundo: reestruturação e perspectivas. BNDES Setorial, no 12, p. 17-50. Rio de janeiro, set. 2001.

IEMI. Brasil têxtil. Relatório do Setor Têxtil Brasileiro. São Paulo, 2014

JORGE, L. H. B.; CASAGRANDE, M. D. H. Análise de Sustentabilidade Ambiental em uma cooperativa produtora de moluscos: Um estudo à luz do SICOGEA Geração 2. In: Encontro Nacional de Gestão Empresarial e Meio Ambiente, 13. São Paulo: EAESPFGV/FEA-USP, 2011.

KAZAZIAN, T. Haverá a idade das coisas leves: design e desenvolvimento sustentável. São Paulo: SENAC, 2005

KONTIC, B. Aprendizado e Metrópole: A reestruturação produtiva da indústria do vestuário em São Paulo. Tese (Doutorado). Departamento de Sociologia da 
Faculdade de Filosofia, Letras e Ciências Humanas da Universidade de São Paulo. São Paulo, 2001

KONTIC, B. Redes Produtivas e Aprendizado da Indústria do Vestuário da RMSP: espaço regional para políticas industriais. In II Encontro da Associação Brasileira de Economia Regional. Anais FEA/USP. São Paulo. 2002

KRAEMER, M. E. P. Responsabilidade Social: uma alavanca para a sustentabilidade. Revista Banas Qualidade, 2005.

LIPOVETSKY, G. O império do efêmero: a moda e seu destino nas sociedades modernas. São Paulo: Companhia das Letras, 2009.

LOBACH, B. Design Industrial. Bases para a configuração dos produtos industriais; tradução Freddy Van Camp. São Paulo. Editorial Blucher, 2001.

MANZINI, E.; VEZZOLI, C. O Desenvolvimento de Produtos Sustentáveis. São Paulo, editora da Universidade de São Paulo, 2005

MELLO, W. B. Proposta de um método aberto de projeto de produto - Três alternativas de criação. Dissertação apresentada à Escola Politécnica da Universidade de São Paulo para obtenção do título de Mestre em Engenharia. Área de Concentração: Engenharia de Construção Civil e Urbana. São Paulo, 2011

MONTEIRO FILHA, D. C. Aplicação de fundos compulsórios pelo BNDES na formação da estrutura setorial da indústria brasileira: 1952-89. Tese de doutorado. Rio de Janeiro, IE/UFRJ, 1994.

NUNES, J. P. O. Um aporte ao sistema contábil gerencial ambiental: elaboração e aplicação parcial do novo sistema em clínica hospitalar. 2010. 241f. Dissertação (Mestrado em Contabilidade), Programa de Pós-Graduação em Contabilidade, Universidade Federal de Santa Catarina, Florianópolis, 2010.

PIQUET, R. Indústria e território no Brasil contemporâneo. Garamond. São Paulo. 2007

POPCORN, F. Click:16 tendências que irão transformar sua vida, seu trabalho e seus negócios no futuro. Rio de Janeiro: Campus, 1997. 
PNUMA. Disponível em:

<http://www.pnuma.org/brasil/AProducaoMaisLimpaeoConsumoSustentavelNaALeC.p df $>$. Acesso em: 24/06/2012.

RIGUEIRAL, C.; RIGUEIRAL, F. Design \& moda: como agregar valor e diferenciar sua confecção. São Paulo: Instituto de Pesquisas Tecnológicas; Brasília, DF: Ministério do Desenvolvimento, Indústria e Comércio Exterior, 2002.

ROZENFELD, H. et al. Gestão de desenvolvimento de produtos: uma referência para melhoria do processo. São Paulo: Editora Saraiva. 2006.

SILVA, Aline Freitas da. O estudo da dimensão social do design sustentável como estratégia para o trabalho do designer na EaD. Belo Horizonte, MG. 2014.

SUZIGAN, W. Indústria Brasileira, origem e desenvolvimento. São Paulo, Brasiliense, 1986. 